\title{
ÉTICA Y ENFERMERÍA
}

Olga Muñoz, Lila Quintero, Josefina Mejia**

En el ejercicio profesionales común escuchar constantes referencias a la ética, pero ¿cuánto se reflexiona sobre este tópico? Es necesario la integración de la ética como base para actuar, sobre todo en áreas que tienen que ver con el manejo de seres humanos, ya que la ética es la ciencia que estudia la conducta y reflexión del comportamiento humano, explica las razones de los actos del hombre y sus cambios, a través del tiempo, en beneficio de la sociedad. Debido a los avances tecnológicos, científicos y a la deshumanización en salud, surgió la necesidad hace aproximadamente 10 años, de reformar el estudio de la ética.'

La Asociación Nacional de Facultades de enfermería, (ACOFAEN) apoyó este propósito y para ello organizó un comité coordinador que, a través del Comité Nacional y los Comités Regionales, cumple con los objetivos de fortalecer y ampliar la ética en Enfermería en el campo docente y asistencial.

Un grupo de docentes de la Facultad de Enfermería de la Fundación Universitaria de Ciencias de la Salud (FUCS) conformó, hace ocho años, un grupo voluntario para el estudio de la ética; en la actualidad, dicho grupo mantiene representación regional y nacional en Acofaen, y está interesado en divulgar su propósito e interactuar con grupos que tengan actividades afines.

Los educadores de enfermería tienen la responsabilidad primordial de la calidad de la enseñanza de enfermería y la competencia de las enfermeras que inician el ejercicio de la profesión, no solamente en cuanto hace referencia a la parte académica sino en el juicio crítico y la ética para la solución de problemas. Esto requiere una educación permanente en el curso de toda la carrera, compartiendo los conoci-

* Facultad de Enfermería, Fundación Universitaria de Ciencias de la Salud. Bogotá, D.C. mientos y experiencias propias con las colegas; la enfermera puede ser educadora, investigadora o una persona que ejerce la profesión y pone a prueba los conocimientos teóricos en la práctica o bien una profesional independiente que vende servicios de enfermería manteniendo el sentido ético y el compromiso con la sociedad. ${ }^{2}$

Siempre se ha reconocido la necesidad de enseñar la ética en las escuelas de enfermería, pero solo en la década de los años 70 ) comenzaron los educadores a examinar los enfoques hacía la enseñanza de la ética en las escuelas de enfermería, los cambios en la atención en salud, la nueva tecnología y el creciente papel de las enfermeras. Las condiciones cambiantes plantearon el interrogante ¿están las enfermeras adecuadamente preparadas para la compleja toma de decisiones éticas y bioéticas en sus papeles nuevos y responsables en la atención de salud?

Para responder a estas preguntas los investigadores comenzaron a analizar los enfoques tradicionales hacia la enseñanza de la ética en las escuelas de enfermería. Un estudio al respecto en los programas de enfermería de los Estados Unidos reveló que el contenido general de la ética estaba integrado en los programas de estudio de los dos tercios de las escuelas examinadas (Ariskan 1977). Esta investigación también reveló la necesidad de enseñar contenidos específicos de la ética de enfermería. Otro estudio de la enseñanza de la ética en enfermería en el Reino Unido indicó que más de $90 \%$ de los programas estudiados consideraban que esta enseñanza debería formar parte específica del programa de enfermería. La mayoría consideraba que la escasez del personal y la falta de tiempo, debido al recargo del programa, le impedía ocuparse debidamente de temas esenciales de ética, con el detenimiento que desearía. ${ }^{3}$ 


\section{Funciones del grupo de estudio de ética y bioética de la FUCS}

- Elaborar un cronograma de actividades y reuniones para el semestre que se basan en los objetivos planeados a corto, mediano y largo plazo.

- Fortalecer el estudio de ética y Bioética en la facultad de enfermería entre docentes y estudiantes.

- Ejercitarse en la resolución de dilemas éticos en la comunidad educativa de la facultad de Enfermería.

- Promover la actualización y capacitación en la ética y bioética entre los docentes.

- Colaborar con el desarrollo de la asignatura de ética para los estudiantes de la facultad de enfermeria.

- Participar activamente en las reuniones del grupo cumpliendo cada uno de los integrantes con las tareas asignadas.

- Participar y representar activamente en las reuniones del comité de ética en el ámbito regional y nacional.

- Estimular a los docentes para realizar investigaciones en el campo de la ética y bioética.

- Avalar en los trabajos de investigación el aspecto ético de la Facultad.

- Proponer artículos o temas de interés al grupo, para discusión.

- Informar en reunión de docentes las actividades del grupo.

- Establecer las normas internas del grupo.

- Participar con artículos de ética y temas afines en los boletines y revistas en asociación científica.

La Asociación Colombiana de Facultades de Enfermería (ACOFAEN), preocupada por esta situación en el ámbito nacional $\mathrm{e}$ internacional, en 1991, recomendó a las facultades de enfermería implementar la ética como asignatura y en cada semestre, así como reforzar el componente ético y bioético en las prácticas. Además, organizó un comité coordinador nacional y regional para promover y divulgar el fortalecimiento de la ética en la docencia y la asistencia.

Atendiendo a tales recomendaciones y con gran motivación por el fortalecimiento de la ética y la bioética, en la Facultad de Enfermería de la Fundación Universitaria de Ciencias de la Salud se conformó un grupo voluntario de docentes, de carácter permanente, encargado de promover, asesorar e investigar el estudio de la ética y la bioética en la facultad de enfermería. Este grupo tiene por objeto promover la formación de profesionales de enfermería moralmente responsables y dotados de la capacidad para tomar decisiones éticas en el ejercicio de la profesión. Para lograrlo, los estudiantes deben aprender a integrar sus valores y convicciones personales con el conocimiento de conceptos éticos, enfoques tradicionales y contemporáneos hacia la ética y normas de comportamiento ético.

Por ser un grupo de estudio, cumple con el primer parámetro que es la educación a través de la capacitación intra y extramural; de esta forma logra la actualización de sus miembros, para hacerla extensiva al colectivo de docentes y estudiantes, a la vez que propende por mantener la autonomía e independencia para las decisiones y funciones del grupo dentro de la estructura y organización de la Facultad de Enfermería.

El grupo no maneja problemas ni conflictos de tipo económico, legal, laboral o administrativo; tan sólo evaluará las dificultades que a la luz de la ética y la bioética presenten implicaciones de principios y valores. Más adelante, cuando haya mayor madurez y experiencia académica puede convertirse en un comité, asumiendo las funciones propias de dicho estamento.

El grupo se reúne periódicamente con el propósito de reflexionar y compartir vivencias profesionales y personales que tengan el componente ético y bioético con el fin de mejorar y aportar al grupo nuevos conocimientos y experiencias que fortalezcan la profesión y sirva de apoyo para la solución de problemas. En la actualidad el grupo de estudio esta conformado por las licenciadas Amparo Benavides, Rosa Coral, Josefina Mejía, Olga Muñoz, Yolanda Muñoz, Lila Quintero y Luz. Dary Quiroga.

\section{Referencias}

1. Balderas P. María de la Luz. Ética de Enfermería. Editorial McGraw-Hill, México. 1998.

2. Rumbold Graham. Ética en Enfermería. Mc Graw-Hill, México. 200() .

3. Fray Sara T. La Ética en la practica de enfermería. Consejo Internacional de Enfermeras. Gincbra Suiza. 1994. 